\title{
Programa de Formação do Patrimônio do Servidor Público
} Análise de suas Principais Características

GERALDO ATALIBA

\author{
Professor nas Faculdades de Direito das \\ Universidades de São Paulo e Católica de São Paulo
}

Foi enviado projeto de lei ao Congresso Nacional instituindo o "programa de formação do patrimônio do servidor público".

$\mathrm{O}$ art. 2 \% do referido projeto prevê o pagamento pela União, Estados, Municípios, Distrito Federal, Territórios e autarquias de "contribuições", correspondentes a um determinado percentual sôbre uma quantia calculada sôbre seus respectivos orçamentos.

No que diz respeito aos Municípios, o referido projeto prevê, no inciso II do art. 2: ${ }^{\circ}$, que êstes - assim como os Estados, "Distrito Federal e os Territórios - concorrerão com $1 \%$ da "receita orçamentária própria", deduzidas as "transferências feitas a outras entidades da administração pública", a partir de 1 ọ de julho de 1971 e progressivamente até chegar êste percentual a $2 \%$.

E, em segundo lugar (b), $2 \%$ das transferências recebidas do Govêrno da União, através dos Fundos de Participação dos Estados e dos Municípios.

Embora redigida de forma pouco clara tal disposição, entende-se que esta última importância será somada àquela anteriormente referida.

Destarte, a contribuição prevista para os Municípios corresponde a $2 \%$ das receitas correntes próprias, mais $2 \%$ das transferências recebidas do Govêrno da União.

Segundo o disposto no art. 4\%, estas "contribuições" serão recolhidas pelo Banco do Brasil e "distribuídas entre todos 
os servidores, em atividade, civis e militares, da União, dos Estados, do Distrito Federal, dos Municípios e dos Territórios, bem como das entidades da administração indireta e das fundações.

Pelas condições estabelecidas no anteprojeto, os servidores beneficiários destas importâncias poderão levantá-las de acôrdo com as expressas previsões aí contidas.

Merece ser detidamente examinada a disposição do art. 8., assim redigido: "A aplicação do disposto nesta lei complementar aos Estados e Municípios, às suas entidades da administração indireta e fundações, bem como aos seus servidores, dependerá de norma legislativa estadual ou municipal".

Parece oportuno especular sôbre qual deverá ser o teor desta lei municipal, prevista no art. 8?, o que faremos em outra ocasião.

Antes de procedermos ao exame dos seus pontos essenciais, importa salientar a absoluta necessidade de definir-se o que se possa conceituar como "receita orçamentária própria"; em segundo lugar, saber como estabelecer critério para determinar a quantia que deverá ser recolhida a partir de 10 de julho de 1971 , à razão de $1 \%$.

É que, se a arrecadação "será feita a partir de 19 de julho de 1971", entretanto, não fica claro qual a base de cálculo que deverá ser levada em consideração. Como claro não está se a receita orçamentária, a que se refere, é aquela prevista na peça orçamentária, ou, pelo contrário, a efetivamente realizada, que poderá ultrapassá-la ou ficar aquém da própria previsão.

Quanto à destinação a êste "programa" de quantias originárias do Fundo de Participação dos Estados e dos Municípios, também parece haver instante necessidade de esclarecimento rigoroso e seguro, que possa ensejar solução ao problema.

Importa qualificar esta transferência compulsória de dinheiro, para êste fundo, rigorosamente em têrmos jurídicos, em face da disciplina constitucional dos deveres, obrigações e direitos das pessoas públicas.

Trata-se de tributo? Especificamente, de contribuição previdenciária? Ou terá outra natureza esta movimentação de dinheiro?

Formulemos algumas indagações, em continuação, para bem nos situarmos e tentarmos vencer a complexidade que se oculta sob a aparente singeleza dêste projeto:

1) Trata-se verdadeiramente de "contribuição"? 
2) Não tendo o "programa" personalidade jurídica, o sujeito ativo será a União?

3) A disposição do art. 8 ?, que prevê norma estadual ou municipal, para a aplicação da lei a Estados e Municípios, respectivamente, porventura conduz à configuração duma figura contratual?

4) Tal contrato classificar-se-ia como de adesão? de 1971?

5) Como determinar a base de cálculo, a partir de julho

6) É esta a contribuição a que se refere o art. $21, \S 2$, $n$ ! I, da Constituição Federal?

7) Referindo-se o projeto, no art. 3 ?, à "receita orçamentária" e sendo o recolhimento mensal, pergunta-se: como determinar a base de cálculo correspondente a cada mensalidade?

Diante dos mandamentos desta lei, por outro lado, importa, ao que nos parece, distinguir a situação da União, Territórios e Distrito Federal, daquela de Estados, Municípios e suas autarquias, situações estas que, por sua vez, não se confundem com as das fundações submetidas a regime de direito privado, embora criadas pelo poder público estadual e municipal, bem como as sociedades mistas e as emprêsas públicas.

A resposta a estas perguntas, desordenadamente formuladas, à medida que foram sendo sugeridas pela leitura de peça tão complexa quão aparentemente singela, poderá ser mais bem encontrada mediante uma sistematização que procuramos adotar.

\section{I) CARACTERISTICAS PRINCIPAIS DO PROJETO}

O projeto de que cuida a mensagem em estudo primeiramente institui um Fundo designado "programa de formação do patrimônio do servidor público", como tal qualificado como "um acervo de dinheiro" movimentado por agentes da União (no caso, o Banco do Brasil), com finalidades específicas ( $\$ \S 3$ ? e 4 ? do art. 5\%).

A configuração dêste acervo como fundo é rigorosamente perfeita, à luz da disciplina que à matéria deu a Lei no 4.320, que disciplina a elaboração de orçamentos e balanços públicos. Seu art. 71 assim dispõe:

"Constitui fundo especial o produto de receitas especificadas que, por lei, se vinculam à realização de 
determinados objetivos ou serviços, facultada a adoção de normas peculiares de aplicação."

Para alimentar de recursos êste fundo, o projeto prevê uma série de medidas, que podem ser classificadas em quatro categorias, nitidamente distintas:

a) destina-Ihe recursos orçamentários da União, dos Territórios, do Distrito Federal e suas autarquias ao referido fundo;

b) destina-lhe dinheiros oriundos dos Fundos de Participação dos Estados e dos Municípios;

c) convida Estados e Municípios a dêle participarem, mediante o concurso de certas importâncias em dinheiro estipuladas no anteprojeto;

d) cria um impôsto, incidente sôbre a receita orçamentária de sociedades mistas, emprêsas públicas e fundações (submetidas a regime de direito privado) criadas por Estados e Municípios, com a peculiaridade, dito impôsto, de ter a sua incidência condicionada à aquiescência da legislação estadual ou municipal, conforme o caso.

A designação "programa de formação do patrimônio do servidor público" nada mais é do que um nome que se atribui ao mesmo fundo, caracterizado êste como o "acervo de dinheiro destinado legalmente a uma determinada finalidade pública".

A mais relevante conseqüência jurídica decorrente da circunstância de o "fundo" ser destituído de personalidade está em que o sujeito de direitos que titulariza êstes recursos é a União, erigida, destarte, à condição de sujeito ativo das relações jurídicas que, com base nesta lei, criar-se-ão.

Isto verificado, passemos ao exame da natureza jurídica dos recursos que alimentarão o fundo e que foram, pela lei, designados "contribuição".

\section{Trata-se de um tributo?}

A primeira vista, sugere o projeto impressão de que, efetivamente, estamos diante de uma imposição unilateral, decorrente de lei e que tem como conseqüência a criação de obrigação a cargo das pessoas aqui designadas - de transferirem para a União, compulsòriamente, uma determinada quantia em dinheiro, o que corresponderia ao conceito doutrinário de tributo.

Melhor exame da matéria ensejará ver que sòmente num caso, bastante restrito, é que vem a se configurar, na verdade, esta figura juridica. Em todos os demais casos não se está diante de fenômeno tributário. 
Entretanto, não há dúvida de que uma série de elementos - que podem ser hauridos da leitura do projeto - fazem supor que assim entenderam seus autores. Efetivamente, parece que os elaboradores do anteprojeto estavam convictos de engendrarem um tributo.

Em primeiro lugar, isto resulta da circunstância de terem recorrido ao veículo "lei complementar". A única razão plausível - que poderia explicar a circunstância de se ter elegido êste veículo - estaria no reconhecimento do desejo de se observar a vedação inscrita no $\S 2$ ? do art. 62 da Constituição Federal, que proíbe a "vinculação do produto da arrecadação de qualquer tributo a determinado órgão, fundo ou despesa". Este mandamento - segundo seus próprios têrmos - sòmente admite exceções à regra, quando decorrentes de disposição expressa da própria Constituição ou de lei complementar.

Naturalmente, entenderam os responsáveis pela elaboração do anteprojeto que estavam diante de uma figura tributária, cujo produto iria reverter para um fundo e que sòmente lei complementar poderia vincular tal destinação.

II) DIVERSA POSIÇÃO DAS DIFERENTES PESSOAS PÚBLICAS EM FACE DO PROJETO

A rigorosa compreensão do conteúdo e do próprio alcance das disposições contidas neste projeto, bem como de seu sistema, considerado como um todo, recomendam que se distinga, rigorosamente, a situação em que se encontram, diante dêsses propostos mandamentos legais, as pessoas da União, Territórios, Distrito Federal e suas autarquias, de um lado, e Estados e Municípios e suas autarquias, de outro.

Diferente ainda é a situação das fundações submetidas a regime de direito privado, criadas por Estados e Municípios, bem como sociedades mistas e emprêsas públicas, criaturas destas pessoas políticas.

Parece evidente que a União, os Territórios e suas autarquias devem imediata obediência à lei federal, pelo que a aplicabilidade desta lei é absoluta e imediata, sem qualquer possibilidade de tergiversação. Tôdas estas pessoas devem imediata obediência a qualquer lei do Congresso.

Já o mesmo, em princípio, não ocorre relativamente a Estados, Municípios e suas autarquias, em razão do princípio federal (art. 13) e do princípio da autonomia municipal (art. 15). 
Estas pessoas políticas e suas criaturas - as autarquias estaduais e municipais - não estariam sujeitas imediatamente à obediência a uma lei expedida pelo Congresso Nacional, versando matéria financeira, salvo a hipótese de norma geral, o que não é o caso.

Desta consideração se vê, em conseqüência, que esta lei nenhum problema oferece, no que respeita à União e suas autarquias, ao Distrito Federal e aos Territórios.

A mesma coisa se diga das emprêsas públicas, sociedades mistas e fundações - estas últimas, quer submetidas a regime público, quer privado - criadas por lei da União.

Em todos êstes casos a aplicabilidade desta lei a estas pessoas é absoluta e imediata.

Bem diversa é a situação dos Estados e dos Municípios, em razão, como dito, do princípio federal e da autonomia municipal. A própria Constituição os coloca fora do alcance de normas que tais.

É bem verdade que o projeto não levou em consideração devidamente esta relevante circunstância, já que, no seu inciso I, contempla a União e, no II, englobadamente, os Estados, Municípios, Distrito Federal e Territórios, como se o regime jurídico de todos êles fôsse idêntico, o que não é exato. Na verdade, os Estados se regem por suas próprias constituições e leis (art. 13) e os Municípios por suas leis, na forma da Constituição Federal (art. 15). São autônomos. Já os Territórios - como meras autarquias territoriais (v. "Natureza e regime jurídico das autarquias", de Celso Antonio Bandeira de Mello, ed. "Revista dos Tribunais", pág. 312) - caem inteiramente sob a autoridade do Congresso.

Quanto ao Distrito Federal - embora não integre a federação e não seja pessoa política - parece que não deverá obediência imediata a esta lei. É que só lei do Senado (art. 42, V) - que é quem "privativamente" pode dispor sôbre seu pessoal, serviço público e orçamento (art. 17, § 10) - poderia impor-lhe tal ônus. Isto não é "nossa opinião", mas interpretação elementar do sistema constitucional, tal como êle é.

Meditação ligeira sôbre o nosso sistema constitucional teria evidenciado que os Territórios estão inteiramente submetidos à legislação federal e, portanto, ao poder do Congresso Nacional, ao contrário do que ocorre com Estados e Municípios; verificação tão elementar que recomendaria, inicialmente, uma distinção das respectivas situações jurídicas e suas conseqüências. 
Estados e Municípios, em razão de sua autonomia, constitucionalmente assegurada, encontram-se, diante desta lei, em situação distinta daquela da própria União e dos Territórios. A aplicabilidade de mandamentos concernentes a recursos financeiros e sua destinação - desde que tais mandamentos sejam federais, e, portanto, estranhos às autonomias mencionadas encontra obstáculo, exatamente, nestas autonomias.

Entretanto, Estados e Municipios, segundo a previsão do inciso II dêsse artigo, concorrem com dois tipos de parcelas para êsse fundo. A primeira, prevista na letra a do inciso II, diz respeito a "receitas correntes próprias", e a segunda (letra b) diz respeito a receitas oriundas do Fundo de Participação dos Estados e do Fundo de Participação dos Municípios, respectivamente.

Estas duas situações também devem ser distinguidas, já que sua disciplina constitucional é diversa.

Efetivamente, as receitas correntes próprias de Estados e Municípios pertencem-lhes com caráter de exclusividade, não havendo possibilidade de ingerência de legislação estranha sôbre a sua destinação.

Por isso mesmo - mui prudentemente e em perfeita consonância com os imperativos mais fundamentais do nosso sistema constitucional - 0 art. 8 ? dêste projeto veio prever que a "aplicação do disposto nesta lei complementar aos Estados e Municípios e às entidades da administração indireta e fundações, bem como aos seus servidores, dependerá de norma legislativa estadual ou municipal".

Quer isto dizer que o implemento dêste mandamento legal, a ser emanado do Congresso, dependerá de expressa aquiescência manifestada pelos Podêres Legislativos estaduais e municipais, em cada caso.

Se assim não dispusesse o projeto, estaríamos diante de uma figura nitidamente tributária, ou seja, "a exigência unilateral de uma determinada parcela de dinheiro - formulada pela União - dos Estados e Municípios", o que seria inconstitucional.

Configurado o tributo, estaríamos diante de insuperável impossibilidade constitucional de efetivar a pretensão em favor da União, já que o princípio da imunidade tributária recíproca - consagrado no art. 19, III, a - impede a exigência recíproca de impostos entre União, Estados e Municípios. 
Como, entretanto, foi condicionada pelo próprio projeto a incidência desta disposição - que prevê a transferência destas parcelas para êste fundo, que é federal - à lei estadual ou municipal, depende sua efetividade da aquiescência de Estados - Municípios, aquiescência esta que será manifestada pelo Poder Legislativo estadual ou municipal, ficando afastada, nitidamente, a figura tributária.

Não se está diante de tributo. Pelo contrário, está-se diante de uma adesão consensual, livremente manifestada, a um programa "proposto" pela União. Se concordarem, Estados e Municípios aderem a êste programa, concorrendo com estas parcelas. Não concordando, ficam dêle excluídos.

\section{III) AFETAÇÃO DE PARCELA DOS FUNDOS DOS ESTADOS E MUNICÍPIOS}

Já, na segunda hipótese (letra $\mathbf{b}, \mathrm{II}$, art. $2{ }^{\circ}$ do projeto), estamos diante de uma "determinação" formulada pelo projeto, no sentido de destinar ao programa $2 \%$ das importâncias que a cada Estado e Município adviriam do Fundo de Participação dos Estados e do Fundo de Participação dos Municípios, respectivamente (Cfo. art. 25 e seu $\S 1$ ? da Carta Federal).

Aqui, também não estamos diante de uma figura tributária. Por outro lado, também não se configura qualquer situação contratual que dependa, portanto, de um consenso, a ser manifestado por Estados e Municípios.

O legislador federal - prevalecendo-se da competência que the outorgou o $\S 1$ ? do art. 25 - irá determinar que a destinação dos fundos de participação dos Estados e dos Municípios, na proporção de $2 \%$, será exatamente esta de concorrer para a formação do acervo que se constituirá no fundo designado "programa de formação do patrimônio do servidor público".

Sendo esta uma faculdade que a Carta Magna Ihe outorgou, - legislador federal dela faz livre uso, em princípio, sem a menor possibilidade de oposição ou resistência por parte de Estados e Municípios. É que o Congresso regula a aplicação dêstes fundos, usando de competência que a Carta Constitucional the concedeu.

Assim sendo, esta parcela de $2 \%$ - prevista na letra b do inciso II do art. 2 \% do projeto - é de aplicação imediata, porque independe de concordância ou aquiescência por parte de Estados e Municípios. Tal "destinação" o Congresso estabelece segundo seu critério. 
Aquiescendo ou não, Estados e Municípios verão $2 \%$ das receitas que the adviriam do fundo de participação respectivo serem destinados a uma certa finalidade, de acôrdo com uma liberdade decorrente de uma competência que o legislador federal já tem, por fôrça, repetimos, do mandamento do § 1 ? do art. 25 da Constituição Federal.

A liberdade que tem o Congresso ao deliberar a respeito não é, entretanto - ao que nos parece - ilimitada. Este texto constitucional não pode ser interpretado fora do contexto constitucional, especialmente da sistemática financeira da Constituição.

\section{IV) AUTARQUIAS E ADMINISTRAÇĀO INDIRETA}

Decorre dos princípios doutrinários entre nós assentes, bem como do nosso sistema constitucional tradicional - o que vem perfeitamente confirmado pela sistemática do anteprojeto em exame -, que as consequuências da manifestação de opção do legislador estadual ou municipal, em cada caso, acarretam conseqüências para as suas autarquias, já que estas, como pessoas meramente administrativas - tal como excelentemente designadas por Ruy Cirne Lima - estão inteiramente subordinadas às determinações do legislador da sua pessoa matriz.

Destarte, as autarquias estaduais e municipais seguem a sorte dos Estados e Municípios a que pertencem e a cuja administração integram.

Distinta é, entretanto, a situação das fundações criadas por Estados e Municípios e submetidas a regime de direito privado (v. "Natureza e regime jurídico das autarquias", Celso Antonio Bandeira de Mello, ed. "Revista dos Tribunais", 1969). Distinta é, também, a situação das sociedades mistas e emprêsas públicas criadas por Estados e Municípios.

Pondo de lado a divergência doutrinária estabelecida entre as correntes dos que sustentam, respectivamente, a possibilidade e a impossibilidade de Estados e Municípios criarem emprêsas públicas e sociedades mistas, vê-se que estas - como pessoas jurídicas de direito privado - , ao se defrontarem com uma obrigação compulsória e unilateral de transferência de recursos para a União, estarão diante, nitidamente, de uma exigência tributária.

É-nos possivel deixar de lado tôda a discussão - em tôrno da possibilidade de Estados e Municípios criarem sociedades mistas e emprêsas públicas - pela circunstância de o sistema 
normativo federal, relativamente ao assunto, ter elidido qualquer margem de discussão, para dar uma solução concreta (v. os excelentes estudos de Moacyr Lobo da Costa, a respeito, na "Revista de Direito Público", vols. 5 e 6, pág. 135).

A diversidade de situações em que se encontram as pessoas políticas (Estados e Municípios), de um lado, e suas emprêsas públicas, sociedades mistas e fundações, de outro, é tão flagrante, que as parcelas com que estas devem concorrer vêm previstas em artigo destacado e diferente, qual seja o 3 ? (do projeto).

Aí se arrolam as "autarquias, emprêsas públicas, sociedades de economia mista e fundações", no que, mais uma vez, incidem em falta de sistema e lucidez de visão os responsáveis pela sua redação, já que não se confundem as autarquias e as demais entidades, salvo as fundações públicas (v. Celso Antonio Bandeira de Mello, "Natureza e regime jurídico das autarquias", ed. "Revista dos Tribunais", São Paulo, 1969).

Por outro lado, também não distingue o projeto as fundações públicas das submetidas a regime de direito privado.

Auxilia a compreensão do alcance e extensão dêste projeto a leitura do seu art. $4^{\circ}$, quando faz referência aos servidores "da União, dos Estados, dos Municípios, do Distrito Federal e dos Territórios, bem como das suas entidades da administração indireta e das fundações".

A designação "entidades da administração indireta" nos indica qual o caminho a ser procurado, para se conhecer exatamente $\mathrm{o}$ alcance e extensão dêstes mandamentos.

Por outro lado, não pode passar sem observação a separação estabelecida, por êsse art. $4{ }^{\circ}$ do projeto, entre fundações e demais órgãos da administração indireta, em assintonia com o previsto nas leis da reforma administrativa (Decretos-leis n.os 200 e 900), que, exatamente, incluem as fundações entre os órgãos da administração indireta.

Não é mesmo de causar mais estranheza encontrar certas hesitações do legislador, nos tempos atuais, quando fixa normas sôbre certos temas. Esta circunstância já foi objeto de aguda crítica do ínclito Seabra Fagundes (R.D.P., vol. 8, pág. 119).

Principalmente no que diz respeito às fundações criadas pelo Poder Público - ou seja, criadas por lei dos Estados ou dos Municípios, mas submetidas a regime de direito privado - 
é preciso verificar-se se não estariam elas subordinadas à legislação que previu a criação do Programa de Integração Social (PIS), destinado às pessoas jurídicas de direito privado, de maneira geral, e já transformado em lei.

A lei já em vigor, que trata do assunto, no seu art. 12, estabeleceu expressamente que:

"Art. 12. As disposições desta lei não se aplicam a quaisquer entidades integrantes da administração pública federal, estadual ou municipal, direta ou indireta, adotando-se, nos três niveis, para efeito de conceituação, como entidades da administração indireta, os critérios constantes dos Decretos-leis n.0s 200, de 25 de fevereiro de 1967 , e 900 , de 29 de setembro de 1969."

A referência à administração "direta ou indireta" aí encontrada, mostra, por exclusão, qual o campo de incidência do projeto que temos diante dos olhos, já que a hermenêtica requer que se leve sempre em consideração a harmonia do sistema, considerado como um todo unitário.

Quanto à conceituação do que seja "administração indireta", não deixou esta lei de dar os critérios normativos para esta decisão, fazendo remissão expressa aos Decretos-leis n.os 200 e 900 .

Efetivamente, analisando-se os conceitos que a êsse respeito trazem os decretos-leis, que tratam da reforma administrativa, mencionados, vê-se que - pelos critérios da reforma administrativa, normativamente adotados - constituem a administração indireta: as autarquias, as emprêsas públicas e as sociedades de economia mista, equiparando-se às emprêsas públicas as fundações instituídas em virtude de lei (art. 4 ㅇ do Decreto-lei n? 900).

Deixando de lado, também, a impropriedade em que se consubstancia a indistinção entre fundações submetidas a regime público ou privado, vê-se que estas são as quatro categorias que integram a administração indireta, segundo o esquema adotado pela "reforma administrativa", uma das mais significativas obras dos governos revolucionários. É pena que não se tenha tentado harmonizar êste anteprojeto com a sistemática do Decreto-lei n? 200.

E verdade que a legislação da reforma administrativa sòmente faz referência à União e sòmente se aplica ao aparelho 
administrativo federal, como decorre de seu próprio texto e do sistema constitucional.

Entretanto, o conceito de administração indireta que foi pressuposto expressamente pelo art. 12 da lei do Programa de Integração Social (PIS) é êste, que, para êstes efeitos, portanto, pode ser estendido, também, aos Estados e Municípios (só para êstes efeitos, sublinhe-se).

E por esta via que se pode conhecer o campo de incidência do projeto que se tem diante dos olhos.

Quando o seu art. 4\% faz referência aos órgãos da administração indireta estadual e municipal, entende-se, por via dêste raciocínio, que se compreendem como órgãos da administração indireta as fundações (sejam públicas, sejam de direito privado), bem como as sociedades mistas e as emprêsas públicas.

Pode-se concluir, portanto, que tôda e qualquer pessoa jurídica de direito privado - revestindo as características de fundação ou de sociedade anônima, ou qualquer outra emprêsa regida pelo direito comercial que se dedica a qualquer tipo de atividade econômica (receba a designação que receber), mas cujo capital seja, majoritàriamente, de propriedade de um poder estadual ou municipal - , estará compreendida dentro dêste conceito de administração indireta e, portanto, excluída do Programa de Integração Social (PIS) e incluída neste programa de formação do patrimônio do servidor público.

Pois bem, em se tratando de pessoa de direito privado, assim reconhecidas pela lei da reforma administrativa - a que faz expressa remissão a legislação dos Programas de Integração Social (PIS) e de formação do patrimônio do servidor, em estudo - tendo elas, diante de si, uma obrigação coativa e unilateral de transferir dinheiros a uma outra pessoa pública (não importa se União, Estado ou Município), está configurado o instituto jurídico do tributo.

A esta situação correspondem não só os conceitos doutrinários como até mesmo aquêles fixados no Código Tributário Nacional.

Para estas pessoas, portanto, a obrigatoriedade prevista no art. 3 ? do projeto - de concorrerem com $0,4 \%$ inicialmente até $0,8 \%$ a partir do ano de 1973 , calculados sôbre sua receita orçamentária -, para estas pessoas, repetimos, se trata de um tributo. 


\section{V) INCIDENCIA CONDICIONAL DA LEI FEDERAL}

É verdade que a incidência e conseqüente obrigatoriedade dêste tributo para estas pessoas submetidas a regime de direito privado vai depender da lei estadual ou municipal prevista no art. 8 ? do projeto em estudo.

Se sobrevier esta lei estadual ou municipal, em cada caso, estaremos diante da possibilidade de incidência da lei federal; não sobrevindo a lei estadual ou municipal, não serão devidas estas importâncias, por tais pessoas.

Em sendo devidas, estará configurado o tributo.

Fixado que, para elas, se trata de tributo - com esta peculiaridade bastante singular de se tratar de tributo com incidência condicionada - tem cabimento perguntar que tipo de tributo é êste.

Reconhece-se a natureza de um tributo pelas peculiaridades e características do seu fato gerador.

Outra coisa não é o que dispõe o art. 4 ㅇ do Código Tributário Nacional.

Deixando de lado as discussões teóricas a respeito do assunto e as conclusões - aliás, já pacíficas e cediças - a êsse respeito (as quais foram adotadas integralmente pelo art. 4 ? do CTN), verificamos que não importa o destino desta arrecadação, no caso, a formação do fundo designado "programa de formação do patrimônio do servidor público", como também não importa a designação recebida.

VI) CONTRIBUIÇÃO?

A lei faz referência a uma "contribuição". O que importa é conhecer o seu fato gerador. Partindo da classificação rigorosamente científica, que toma por critério a consistência do próprio fato gerador, para distinguir entre aquêles vinculados e não vinculados, podemos reconhecer que estamos diante, nitidamente, de uma hipótese de tributo não vinculado.

É que a base de cálculo, como muito bem ensina a doutrina e como ficou exposto com magistral clareza por ALFREDO AUGUSTO BECKER, é o elemento essencial do fato gerador. Pois a base de cálculo dêste tributo, tal como prevista pelo art. 3 ? do projeto, é a receita orçamentária destas pessoas privadas.

Assim sendo, vê-se que o fato gerador consiste, no caso, num atributo destas pessoas privadas, que nenhuma relação 
direta ou indireta guarda com qualquer tipo de atividade desempenhada pela União, referentemente a estas mesmas pessoas. pôsto.

Em razão disto, fica aí evidentemente configurado o im-

Se confrontarmos esta situação concreta com o art. 16 do Código Tributário Nacional, vamos verificar que efetivamente estamos diante de um impôsto. Efetivamente, o art. 16 do CTN dispõe que:

"Impôsto é o tributo cuja obrigação tem como fato gerador uma situação independente de qualquer atividade estatal específica, relativa ao contribuinte."

$\mathrm{Na}$ verdade, a receita orçamentária destas pessoas privadas é situação ou coisa que independe inteiramente de qualquer atividade da pessoa exigente (União) relativamente a elas. Esta "independência" a que, com rara felicidade, alude o CTN corrobora nossa classificação de tal tributo como "não vinculado" (v. nossos "Apontamentos de ciência das finanças, direito financeiro e tributário").

Parece-nos indiscutivel, portanto, que, efetivamente, estamos diante de uma figura de impôsto.

Para as pessoas de direito privado que integram a chamada administração indireta, para os efeitos de aplicação desta lei, esta chamada contribuição é nìtidamente impôsto.

VII) COTEJO ENTRE AS DISPOSIÇŌES DO PROJETO
E A DISCIPLINA DAS CONTRIBUIÇÕES PREVISTA NA CONSTITUIÇÃO FEDERAL

Como visto, estas parcelas - com as quais tôdas as pessoas designadas concorrerão para a formação do "programa" objeto dêste projeto - têm caráter tributário para as entidades de direito privado criadas por Estados e Municípios, e não têm caráter tributário para as demais pessoas contempladas no projeto.

Afirmou-se e demonstrou-se, inclusive, que para as pessoas privadas criadas por Estados e Municípios se trata de um impôsto.

$E$ de se perguntar, então, se as referências que contém 0 projeto à palavra "contribuição" (parágrafo único do art. 2 ? e art. 4?) efetivamente correspondem ao conceito científico desta. 
Se os responsáveis pela elaboração dêste anteprojeto quiseram atribuir-lhe o regime (e a designação) de lei complementar é porque pensaram estar diante de entidade tributária.

Em nenhuma passagem se encontra, no projeto, referência a impôsto ou taxa.

Pelo contrário, por duas vêzes se encontra a expressão "contribuição" (parágrafo único do art. 2 ? e art. 4ํ).

Disto tudo se dessume ser lícito atribuir aos responsáveis pela elaboração do anteprojeto a intenção de criar uma contribuição.

A quem percorra com os olhos a legislação editada pelos governos revolucionários - que vieram excepcionar e depois revogar o regime da Constituição de 1946 - não causa estranheza o encontrar a designação "contribuição" errôneamente aplicada a impostos ou taxas. O conceito de contribuição ainda está muito confuso na nossa legislação, como infirme na doutrina.

Este é o caso da chamada "contribuição" para o Banco Nacional da Habitação, "contribuição" para o Banco Nacional de Crédito Cooperativo etc. Inúmeras foram as designações de "contribuição" que surgiram ùltimamente, na legislação federal.

Nenhuma novidade se encerra em descobrir-se que essas "contribuições" não correspondem ao conceito doutrinário.

Não surpreende isto, já que a própria chamada "contribuição previdenciária", prevista no inciso XVI do art. 156 da Constituição Federal, não é uma contribuição verdadeira e própria (v. nosso "Sistema Constitucional Tributário", pág. 187 e segs.).

Em coerência, portanto, com esta tradição de designar errôneamente entidades tributárias, vem agora êste projeto trazer mais uma "contribuição", que não corresponde ao conceito científico.

Das "contribuições" trata o inciso I do $\S 2$. do art. 21 da Constituição Federal.

Prevê esta disposição que

"a União pode instituir: I - contribuição... tendo em vista intervenção no domínio econômico e o interêsse da previdência social, ou de categorias profissionais;".

A única inteligência coerente que se pode atribuir a esta disposição é aquela no sentido de prestigiar uma distinção 
entre esta entidade tributária (contribuição) e os impostos e as taxas, que vêm - dentro do Sistema Constitucional Tributário - previstos separadamente.

Assim sendo, estas contribuições não se podem confundir quer com os impostos, quer com as taxas.

Ora, está visto que a chamada "contribuição" prevista neste projeto - para União, Distrito Federal, Territórios e suas pessoas da administração indireta, assim como para Estados e Municípios - não reveste caráter tributário, não se cogitando, portanto, de classificar como sendo esta subespécie tributária.

Com relação às pessoas submetidas a regime de direito privado, integrantes da administração indireta de Estados e Municípios, isto configura um tributo; mas já se verificou que se trata de impôsto.

A primeira vista, parece que a contribuição prevista neste projeto preenche os requisitos da disposição do inciso I do $\S 2$ ? do art. 21 da Carta Federal, já que ela atende aos interêsses da previdência social, quando preenche algumas das finalidades previstas no inciso XVI do art. 165 da Constituição vigente.

Efetivamente, ela atende aos servidores públicos em casos de doença, velhice, invalidez, morte. Por outro lado, trata-se de tributo estabelecido em benefício de categorias profissionais.

Como é sabido, o princípio da imunidade tributária recíproca previsto no art. 19, III, a, sòmente cobre os impostos, não se estendendo às taxas e contribuições.

Os responsáveis pela elaboração dêste projeto estavam bem conscientes disto e, no entanto, previram a aquiescência do legislador estadual ou municipal para a incidência destas exigências, relativamente a Estados e Municípios, e entidades da sua administração indireta.

Ora, isto evidencia claramente que êles tinham convicção de não estarem diante de uma contribuição, já que a lei federal poderia impor contribuição, sem necessidade da concordância de Estados e Municípios.

Ocorre que o obstáculo à exigência de mais uma contribuição com finalidade previdenciária estaria na circunstância de já haver a legislação - consubstanciada na Lei Orgânica da Previdência Social - regulamentado o inciso XVI do art. 165 da Constituição Federal.

Estaríamos, então, diante da hipótese de dupla exigência de um mesmo tributo, relativamente a Estados e Municípios, 
com infringência da sistemática prevista na própria Lei Orgânica da Previdência Social, rigorosamente adequada aos cânones sistemáticos da Constituição.

Por outro lado, o simples confronto da disposição do parágrafo único do art. 163 da Constituição com o § 1 ọ do art. 166 bem evidencia que não se trata, quer da contribuição - que pode ser instituída por lei federal, para atender à intervenção no domínio econômico - , quer, no caso, de contribuição em benefício de associação profissional ou sindical.

E a consideração sôbre os elementos constitutivos do fato gerador dêste tributo (tributo - como visto - só para as entidades submetidas a regime de direito privado e que integram a administração indireta dos Estados e dos Municípios) bem evidencia que estamos diante de exação que deve ser classificada como não vinculada, e, em conseqüência, excluindo o reconhecimento de uma contribuição, no caso.

VIII) DISCERNIMENTO ENTRE O CAMPO DE INCIDENCIA DO PROGRAMA DE INTEGRAÇÃO SOCIAL (PIS) E DO PROGRAMA DE FORMAÇÃO DO PATRIMÔNIO DO SERVIDOR PÚBLICO

O Programa de Integração Social (PIS) cobre o campo das emprêsas privadas, e o programa de formação do patrimônio do servidor - em estudo - o setor dos serviços públicos, vale dizer: a administração, assim direta como a indireta.

Não importa que certos órgãos da administração indireta estejam submetidos a regime de direito privado (como as sociedades mistas, emprêsas públicas ou fundações de direito privado criadas pelo poder público). Em tôdas estas hipóteses - desde que se configure o que os Decretos-leis n.cs 200 e 900 designam por administração indireta - não incide o PIS para dar lugar à aplicação da lei cujo projeto aqui estudamos.

\section{IX) CONCLUSÃO}

As principais indagações aqui levantadas podem ser respondidas, sintèticamente, à vista de todo o exposto, da seguinte forma:

1. Receitas correntes próprias são aquelas realizadas pelas pessoas constitucionais, excluídas as receitas "de transferência", tal como classificadas pela Lei no 4.320. 
2. Sendo o sistema orçamentário sempre decomponível em duodécimos, e referindo-se o projeto a "recolhimentos mensais" (art. 2), o cálculo destas importâncias há de ser sôbre as receitas realizadas mês a mês.

3. O cálculo há de ser sôbre a receita orçada (prevista), já que a receita "realizada" só é apurável com muito tempo de atraso.

4. Para Estados e Municípios configura-se contrato de adesão, a ser livremente pactuado.

5. Para as pessoas submetidas a regime de direito privado criadas por Estados e Municípios, integrantes de sua administração indireta, é impôsto.

6. A lei estadual ou municipal, conforme o caso, deverá vir dispor que o Executivo fica autorizado a firmar convênio com a União para o fim de integrar os servidores estaduais ou municipais (conforme o caso) no "programa".

7. Na ausência de lei estadual ou municipal, o Estado ou Município interessado (conforme o caso) fica excluído do "programa" e, via de conseqüência, sem os ônus correspondentes.

A decisão a respeito fica inteiramente a critério do legislador estadual ou municipal, de acôrdo com os princípios constitucionais, com os quais afina a disposição do art. 8 ? do projeto. 